\title{
Correspondence
}

Epidemiol. Infect.

doi:10.1017/S0950268807008291

(First published online 12 March 2007)

\section{Epidemic influenza and vitamin D}

To the Editor:

We were very interested to see this very thorough article [1] and welcome its particular acknowledgement of the pioneering work of Hope-Simpson.

Vitamin D deficiency states are associated with both inadequate diet and limited exposure to sunlight and there are clearly risk populations especially among the elderly who are likely to become vitamin D deficient. In consequence, they might have an increased likelihood of infections generally and of the more severe manifestations of influenza in particular. However, the converse argument is not so persuasive. Only a minority of persons who experience influenza are likely to be vitamin D deficient and certainly not enough to materially affect herd immunity thereby interfering with transmission of influenza viruses. We would like to use this opportunity to air an alternative hypothesis on the seasonality of influenza: this is offered as a development of 'Proposition Number 1' as articulated by Hope-Simpson, which concerned the lack of spread of influenza [2].

Influenza is clearly a seasonal condition which very rarely reaches epidemic proportions during summer months, whether north or south of the equator. Accepting that influenza is transmitted (along with many other respiratory virus infections) mainly by respiratory droplets, then it follows that anything interfering with the transmission of viruses in such droplets will inhibit spread. Perhaps ultraviolet (UV) radiation effectively reduces the likelihood of transmission of influenza viruses by substantially reducing the number of viruses which are transmitted in this way because they are 'killed' by UV exposure. Laboratory experiments have demonstrated the inactivating properties of UV radiation against a number of viral pathogens including influenza [3, 4]. The Weekly Returns Service of the Royal College of General Practitioners has recorded a declining trend in the incidence of respiratory infections (particularly influenza-like illness) over the last two decades and it is possible that this may, in part, be due to increasing levels of environmental UV radiation [5, 6]. This hypothesis on the transmission of influenza in relation to UV differing levels of exposure would need to be tested in an appropriate animal model.

The hypothesis is consistent with many features typically associated with influenza.

(1) Historically it has long been observed that winter weather conditions precipitate epidemics of infection. These conditions include reduced daylight, increased particulate matter in the atmosphere and often overcast and cloudy conditions all of which reduce the penetration of UV radiation. A small increase in the potential of one person to pass the illness onto another would accelerate the spread of influenza in a susceptible community. There has to be a minimum value of the reproduction number $\left(R_{0}\right)$ in order to sustain transmission at all. Perhaps in conditions of high UV exposure this number at a community level falls consistently below that minimum.

(2) Pandemics have always been described as coming in waves. Why does one wave peter out in circumstances where the population immunity is low? The virus has not disappeared and there are still substantial numbers in the community who are susceptible. Since this petering out invariably comes during periods of increased light intensity, the virucidal effects of UV light may be curtailing spread. The Sydney strain of influenza $\mathrm{A} / \mathrm{H}_{3} \mathrm{~N}_{2}$ appeared in March 1997 in the United Kingdom and although it had a sharp impact in close communities such as the elderly in nursing homes, it did not spread substantially to the population until the following winter. 
(3) Influenza viruses presenting in one hemisphere do not get to the other at the same time of the year, even though they appear in east/west differing populations the same distance away. Excess winter mortality is largely linked to the incidence of respiratory infections (not only influenza) as the major cause. However, excess winter mortality levels differ in ways that are not easily understood [7]. Part of the difference must relate to the density of population and level of personal interaction which might favour the spread of respiratory droplet infections and weather conditions may be relevant, in particular the levels of UV exposure. Fifty years ago it was common practice to send persons with tuberculosis to sanatoria in the mountains in Switzerland. Perhaps the benefits they obtained in regard to the management of tuberculosis were chiefly because they were living in an environment of clean air and high UV exposure resulting in a reduced likelihood of secondary respiratory infections.

Further support is presented in the study published by Yusuf and colleagues who investigated the relationship between meteorological conditions and respiratory syncytial virus (RSV) infection [8]. UVB radiation was inversely related to the incidence of RSV in most locations investigated, although they considered the effects were attributable to a combination of meteorological conditions which included UVB radiation. Whilst these authors concentrated on the importance of UVB radiation in the synthesis of vitamin $\mathrm{D}$, their final sentence is particularly significant: ' $U V B$ irradiation may also be useful in reducing the survival of RSV in closed spaces.'

\section{Declaration of Interest}

None.

\section{References}

1. Cannell JJ, et al. Epidemic influenza and vitamin D. Epidemiology and Infection 2006; 134: 1129-1140.

2. Hope-Simpson RE. The Transmission of Epidemic Influenza. New York: Plenum Press, 1992.

3. Hollaender A, Oliphant JW. The inactivating effect of monochromatic ultraviolet radiation on influenza virus. Journal of Bacteriology 1944; 48: 447-454.

4. Jensen MM. Inactivation of airborne viruses by ultraviolet irradiation. Applied Microbiology 1964; 12: 418420.
5. Elliot AJ, Fleming DM. Surveillance of influenza-like illness in England and Wales during 1966-2006. Eurosurveillance 2006; 11: 249-250.

6. Pearson AJ, et al. HPA solar radiation measurements in the UK during 2004 and 2005. HPA Centre for Radiation, Chemical and Environmental Hazards, 2006.

7. Crombie DL, et al. Concurrence of monthly variations of mortality related to underlying cause in Europe. Journal of Epidemiology and Community Health 1995; 49: 373378.

8. Yusuf S, et al. The relationship of meterological conditions to the epidemic activity of respiratory syncytial virus. Epidemiology and Infection 2007. doi:10.1017/ S095026880600776X

D. M. FLEMING AND A.J. ELLIOT

Birmingham Research Unit of the Royal College of General Practitioners

Address correspondence to:

Dr D. M. Fleming, The Birmingham Research Unit of the Royal College of General Practitioners, 54 Lordswood Road, Harborne, Birmingham B17 9DB, UK.

(Email: dfleming@rcgpbhamresunit.nhs.uk)

\section{The authors reply:}

We thank Drs Fleming and Elliot for their kind response to our recent hypothesis that the seasonality of 25-hydroxy-vitamin D [25(OH)D] levels explains the seasonality of epidemic influenza [1]. We emphasize that we-like Hope-Simpson-limited our theory to epidemic influenza, not pandemic influenza. Some of the evidence we presented, such as summertime scarcity and higher incidence among African Americans, did not hold true for the 1918 pandemic [2]. In addition, of the 125 mainly pandemics recorded before 1918, 50 occurred in the winter, 35 in the spring, and 24 in the autumn; but 16 occurred in the summer [2, p. 489]. It would be a mistake to overstate the potential role of vitamin $\mathrm{D}$, which is likely to play a key role in innate immunity, but might be less effective facing a virus as virulent as the one that devastated the world in 1918.

We know of no evidence to support or refute Fleming and Elliot's statement that 'Only a minority of persons who experience influenza are likely to be vitamin D deficient and certainly not enough to affect herd immunity materially thereby interfering with transmission of influenza viruses.' The incidence of vitamin D deficiency depends entirely on how one defines it. If it is anything less than $25(\mathrm{OH}) \mathrm{D}$ levels 
achieved by natural summertime sun exposure (50 ng/ $\mathrm{ml}$ ), then almost all humans residing in temperate latitudes are vitamin $\mathrm{D}$ deficient, at least in the winter [3]. To our knowledge, it is unknown if such levels affect the transmission of the influenza virus and thus herd immunity.

If solar radiation is retarding influenza transmission by directly killing the virus, as Fleming and Elliot propose, then it must do so outdoors. As UVC radiation does not penetrate the atmosphere, UVB radiation does not penetrate glass, and UVA radiation does not penetrate solid structures such as buildings, cars, or subway trains, then UV light should have no effect indoors where most human contagion surely occurs.

Gigineishvili et al. found brief courses of UV radiation reduced respiratory infections in athletes by $50 \%$ and absenteeism by $300 \%$ compared to nonirradiated controls over 3 years [4]. The twice yearly courses of radiation were only administered for about 15 minutes a day, three times a week, for 12 weeks. Thus, the subjects were irradiated for only 27 of the 26280 hours in the 3 years. If direct UV inactivation of the virus explains these results, we find it difficult to understand how it could do so when the subjects were irradiated briefly and not continuously. At least five other studies have found such brief courses of vitamin D-producing radiation reduce the incidence of viral respiratory infections [5-9].

In 1951, Gelperin et al. directly investigated the direct UV inactivation hypothesis, at least as regards influenza transmission by aerosols [10]. For 4 months during the height of the cold and influenza season, the authors carefully irradiated only the upper air in half the classrooms of eight New Haven schools, taking great care not to irradiate the students, either directly or indirectly. When they compared absenteeism in irradiated classrooms to non-irradiated control classrooms, they found no effect from irradiation. Two other large field studies likewise showed no effect from UV air irradiation [11, 12].

A study of the 1957-1958 pandemic - which is frequently cited as proof of influenza transmission by aerosols - found quite different results. McLean, as part of a general discussion in a paper by another author, reported that the 150 patients on a 'totally radiated' California TB ward had a $2 \%$ influenza attack rate while the 250 'non-radiated' patients had a $19 \%$ attack rate [13]. Inspection of an earlier publication by the same authors about a similar hospital clearly shows that in addition to irradiating circulating air, the rooms and hallways of the 'totally radiated' ward were all equipped with UV lights that shone directly on patients, apparently the entire waking day [14]. Such radiation should have significantly raised the $25(\mathrm{OH}) \mathrm{D}$ levels of the relatively influenza-free patients.

Finally, as Fleming and Elliot point out, vitamin D-producing sunlight was successfully used to treat $\mathrm{TB}$ in the early part of the last century. However, brief courses of artificial UV light were used as well. In fact, the 1903 Nobel Prize in Medicine or Physiology was awarded to Dr Niels Finsen for his discovery that artificial UV radiation cured tuberculosis of the skin (lupus vulgaris) [15]. It is commonly assumed that Finsen's discovery was due to direct UV effects on the skin and thus only relevant to skin infections. In fact, Finsen and others extended his work to all forms of internal tuberculosis. By 1925, the American Medical Association was comfortable enough with the scientific evidence to issue the following statement.

The benefit derived by patients suffering from tuberculosis of the bones, articulations, peritoneum, intestine, larynx and lymph nodes when exposed to natural sunlight or to the rays emitted by certain artificial sources of radiation cannot be doubted ... [16].

Sir Almroth Wright, one of the founders of immunology - writing in the 1929 edition of the Encyclopaedia Britannica-summed up the mechanism of action as known at the time:

As has been shown in the irradiation of the skin with ultraviolet light, the light of the electric arc and sunlight that by these agencies also the bactericidal power of the blood is increased, such bactericidal power depending upon the increased phagocytic power of the leucocytes and also upon the increased antibacterial power of the serum. It is not yet known how irradiation produces these results [17].

Subsequently, vitamin D-producing artificial UV radiation and sunbathing in open air sanitariums was reported to be effective treatment for a variety of infectious diseases and was widely practised in the 1920s and 1930s (for a critical review see Albert \& Ostheimer [18]). The mechanism of action we referenced in our influenza paper-increased production of antimicrobial peptides by vitamin D - may be the long-lost explanation for UV light's effectiveness. We hypothesize that any infectious disease that is susceptible to vitamin D-induced antimicrobial peptides is a potential target.

While the theory that UV light directly destroys the influenza virus might explain some of the 
observations we referenced, it cannot explain them all. Why do non-rachitic vitamin D-deficient children have an 11 times higher incidence of lower respiratory infections? [19]. Why are age-adjusted influenza deaths during epidemics more common among African Americans than among whites? [20-22]. Why are the fevers caused by the intranasal administration of attenuated influenza virus so much more evident during the winter than the summer? [23, 24]. Why does cod liver oil [25-27] and supplemental vitamin $\mathrm{D}$ [28] reduce the incidence of viral respiratory infections? The vitamin D theory parsimoniously explains all the facts we presented. If there are relevant facts, which we did not reference and that contradict our theory, we invite their presentation.

\section{Declaration of Interest}

Dr Cannell heads the non-profit educational group, 'The Vitamin D Council'.

\section{References}

1. Cannell JJ, et al. Epidemic influenza and vitamin D. Epidemiology and Infection 2006; 134: 1129-1140.

2. Jordan EO. Epidemic Influenza, a Survey. Chicago: American Medical Association, 1927.

3. Heaney RP. The vitamin D requirement in health and disease. Journal of Steroid Biochemistry and Molecular Biology 2005; 97: 13-19.

4. Gigineishvili GR, et al. The use of UV irradiation to correct the immune system and decrease morbidity in athletes [in Russian]. Voprosy Kurortologii, Fizioterapii, i Lechebnoi Fizicheskoi Kultury 1990; 3: 30-33.

5. Bezberkhaia T. The toughening of boarding school students by ultraviolet radiation [in Russian]. Gigiena i Sanitaraii 1963; 28: 94-97.

6. Andrianova AI. Prophylactic ultraviolet irradiation of preschool children of Moscow [in Russian]. Gigiena i Sanitaraii 1970; 35: 30-33.

7. Allen RM, Cureton TK. Effects of ultraviolet radiation on physical fitness. Archives of Physical Medicine 1945; 26: 641-644.

8. Maughan GH, Smiley DF. The effect of general irradiation with ultraviolet light upon the frequency of colds. Journal of Preventative Medicine 1928; 2: 6977.

9. Maughan GH, Smiley DF. Irradiations from a quartzmercury-vapor lamp as a factor in the control of common colds. American Journal of Hygiene 1929; 9: 466-472.

10. Gelperin A, Granoff MA, Linde JI. The effect of ultraviolet light upon absenteeism from upper respiratory infections in New Haven schools. American Journal of Public Health 1951; 41 : 796-805.
11. Kingston D, Lidwell OM, Williams RE. The epidemiology of the common cold. III. The effect of ventilation, air disinfection and room size. Journal of Hygiene 1962; 60: $341-352$.

12. Medical Research Council. Air disinfection with ultraviolet irradiation: its effect on illness among school children. London: Her Majesty's Stationery Office, 1954. Special Report Series No. 283.

13. Jordan WS. The mechanism of spread of Asian influenza. American Review of Respiratory Diseases 1961; 83: 36-38.

14. Riley RL, et al. Air hygiene in tuberculosis: quantitative studies of infectivity and control in a pilot ward. American Review of Tuberculosis 1957; 75: 420-431.

15. The Nobel Foundation (http://nobelprize.org/nobel_ prizes/medicine/laureates/1903/finsen-bio.html). Accessed 1 January 2007.

16. Council on Physical Therapy. Regulation to govern advertising of ultraviolet generators to the medical profession only. Journal of the American Medical Association $1925 ; 98$ : 400 .

17. Wright, Sir A. Immunity. In: Encyclopaedia Britannica, 14th edn, 1929; vol, 12, p. 117.

18. Albert MR, Ostheimer KG. The evolution of current medical and popular attitudes toward ultraviolet light exposure: part 1. Journal of the American Academy of Dermatology 2002; 47: 930-937.

19. Wayse V, et al. Association of subclinical vitamin D deficiency with severe acute lower respiratory infection in Indian children under $5 \mathrm{y}$. European Journal of Clinical Nutrition 2004; 58: 563-567.

20. Minino AM, et al. Deaths: final data for 2000. National vital statistics reports: from the Centers for Disease Control and Prevention, National Center for Health Statistics, National Vital Statistics System 2002; 50, $1-119$.

21. Arias E, et al. Deaths: final data for 2001. National vital statistics reports: from the Centers for Disease Control and Prevention, National Center for Health Statistics, National Vital Statistics System 2003; 52, 1-115.

22. Kochanek KD, et al. Deaths: final data for 2002. National vital statistics reports: from the Centers for Disease Control and Prevention, National Center for Health Statistics, National Vital Statistics System 2004; 53, 1-115.

23. Shadrin AS, Marinich IG, Taros LY. Experimental and epidemiological estimation of seasonal and climatogeographical features of non-specific resistance of the organism to influenza. Journal of Hygiene, Epidemiology, Microbiology, and Immunology 1977; 21: 155161.

24. Zykov MP, Sosunov AV. Vaccination activity of live influenza vaccine in different seasons of the year. Journal of Hygiene, Epidemiology, Microbiology, and Immunology 1987; 31: 453-459.

25. Holmes AD, et al. Vitamins aid reduction of lost time in industry. Journal of Industrial and Engineering Chemistry 1932; 24: 1058-1060.

26. Holmes AD, et al. Cod liver oil - a five-year study of its value for reducing industrial absenteeism caused by 
colds and respiratory diseases. Industrial Medicine 1936; 5: 359-361.

27. Linday LA, et al. Effect of daily cod liver oil and a multivitamin-mineral supplement with selenium on upper respiratory tract pediatric visits by young, innercity, Latino children: randomized pediatric sites. Annals of Otology, Rhinology, and Laryngology 2004; 113: 891-901.

28. Rehman PK. Sub-clinical rickets and recurrent infection. Journal of Tropical Pediatrics 1994; 40: 58.

J. J. CANNELL ${ }^{1}$, R. VIETH ${ }^{2}$, J.C. UMHAU ${ }^{3}$, M. F. HOLICK ${ }^{4}$, W. B. GRANT ${ }^{5}$, S. MADRONICH ${ }^{6}$, C. F. GARLAND ${ }^{7}$

AND E. GIOVANNUCCI ${ }^{8}$

${ }^{1}$ Atascadero State Hospital, Atascadero, CA ; ${ }^{2}$ Department of Medicine, Pathology and Laboratory Medicine, Mount Sinai Hospital, Toronto, Ontario, Canada ; ${ }^{3}$ Laboratory of Clinical and Translational Studies, National Institute on Alcohol Abuse and Alcoholism, National Institutes of Health, Bethesda, MD; ${ }^{4}$ Departments of Medicine and Physiology, Boston University School of Medicine, Boston, MA; ${ }^{5}$ Sunlight, Nutrition, and Health Research Center (SUNARC), San Francisco, CA; ${ }^{6}$ Atmospheric Chemistry Division, National Center for Atmospheric Research, Boulder, CO, USA; ${ }^{7}$ Department of Family and Preventive Medicine, University of California San Diego, La Jolla, CA; 8 Departments of Nutrition and Epidemiology, Harvard School of Public Health, Boston, MA

Address correspondence to:

Dr J. J. Cannell, Atascadero State Hospital, 10333 El Camino Real, Atascadero, CA 93423, USA.

(Email: jcannell@dmhash.state.ca.us)

Epidemiol. Infect.

doi:10.1017/S0950268807008308

(First published online 12 March 2007)

\section{To The Editor:}

The occurrence of the common cold and influenza shows clear seasonality. The cold and influenza season corresponds to the season of vitamin D insufficiency. This association was highlighted in the recent article in this journal by Cannell et al. [1], which proposed that the lack of vitamin $\mathrm{D}$ during the winter may be a 'seasonal stimulus' to the infectivity of the influenza virus.

Vitamin D is produced in the skin when sunlight is absorbed. Thus, vitamin D levels, or serum 25hydroxyvitamin D (25-OHD), fluctuate seasonally. At latitudes above $37^{\circ} \mathrm{N}$ and below $37^{\circ} \mathrm{S}$, sunlight is insufficient to induce cutaneous vitamin $\mathrm{D}$ synthesis during the winter months so 25-OHD levels are low [2]. New evidence has accumulated that vitamin
D can have important functions in the immune system, specifically the innate immune system. Is our susceptibility to colds and influenza related to vitamin $\mathrm{D}$ insufficiency in the wintertime? Furthermore, would vitamin $\mathrm{D}$ supplementation boost our immune system and work as a preventive measure for colds and influenza?

We considered these questions after reviewing the adverse events of a vitamin D3 supplementation trial that we completed [3]. The design and primary results of the study have been published and are summarized here. We conducted a 3-year randomized controlled trial to test the hypothesis that vitamin D3 supplementation would prevent bone loss in calcium-replete, African-American post-menopausal women. A total of 208 women were randomized to receive vitamin D3 $(n=104)$ or placebo $(n=104)$. After 2 years, the vitamin D3 dose was increased to $50 \mu \mathrm{g} / \mathrm{d}$ (2000 IU) in the active group. None of the patients had a history of chronic obstructive pulmonary disease, congestive heart failure, or myocardial infarction. Few patients had a history of asthma and seasonal allergies with no significant difference between the vitamin D3 group and the placebo group.

The study was approved by the Institutional Review Board of Winthrop University Hospital. After randomization, patients were followed up every 6 months for 3 years. At each visit, information on URI symptoms was obtained by first asking the participants, 'Have you been well?' If the participant answered 'No', then she was asked, 'Have you had any colds or influenza?' A report of cold and influenza was recorded as an adverse event.

After 3 years, a total of 34 patients reported cold and influenza symptoms, eight in the vitamin D3 group vs. 26 in the placebo group $(P<0 \cdot 002)$. When we examined the seasonality of the symptoms, we found that the placebo group had cold/influenza symptoms mostly in the winter. The vitamin $\mathrm{D}$ group had symptoms throughout the year while on $20 \mu \mathrm{g} / \mathrm{d}$, whereas only one subject had a cold/influenza while on $50 \mu \mathrm{g} / \mathrm{d}$ (Fig.). None of the 34 patients with reported cold and influenza symptoms had significant comorbidities.

Vitamin D supplementation, particularly at higher doses, may protect against the 'typical' winter cold and influenza. A major flaw in this analysis is that the data on viral URI symptoms were collected in an insensitive and imprecise way. From a 3-year trial on 208 subjects, we would expect at least 139 colds, but we only collected 39 reports of viral URI symptoms, 